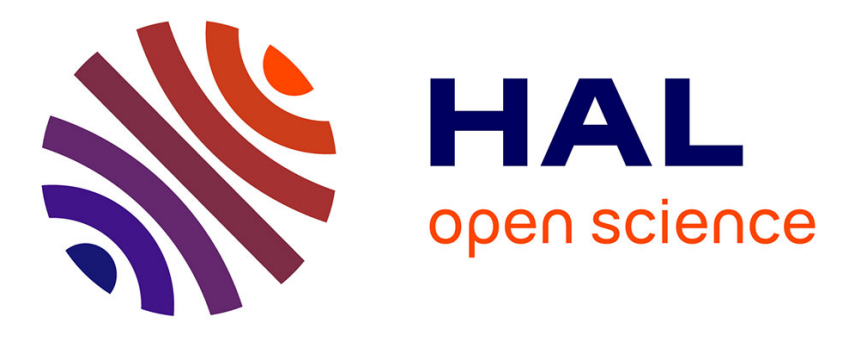

\title{
Novel insight into the chemical analysis of light elements in oxycarbides
}

\author{
Florian Rejasse, O. Rapaud, J. Léchelle, Gilles Trolliard, H. Khodja, Olivier \\ Masson, G. Martin, Alexandre Maitre
}

\section{- To cite this version:}

Florian Rejasse, O. Rapaud, J. Léchelle, Gilles Trolliard, H. Khodja, et al.. Novel insight into the chemical analysis of light elements in oxycarbides. Acta Materialia, 2018, 157, pp.11-20. 10.1016/j.actamat.2018.07.023 . cea-01837208

\section{HAL Id: cea-01837208 https://hal-cea.archives-ouvertes.fr/cea-01837208}

Submitted on 12 Jul 2018

HAL is a multi-disciplinary open access archive for the deposit and dissemination of scientific research documents, whether they are published or not. The documents may come from teaching and research institutions in France or abroad, or from public or private research centers.
L'archive ouverte pluridisciplinaire HAL, est destinée au dépôt et à la diffusion de documents scientifiques de niveau recherche, publiés ou non, émanant des établissements d'enseignement et de recherche français ou étrangers, des laboratoires publics ou privés. 


\section{Novel insight into the chemical analysis of light elements in oxycarbides}

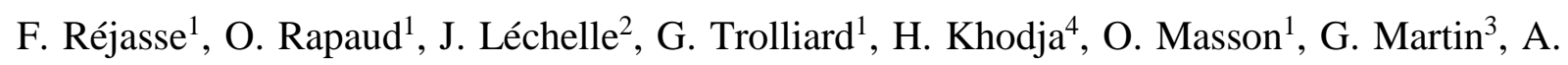
Maître ${ }^{1}$

${ }^{1}$ IRCER, CNRS, Univ. Limoges, UMR 7315, Centre Européen de la Céramique (CEC), 12 Rue Atlantis, F-87068 Limoges Cedex, France

${ }^{2}$ CEA Cadarache, DEN/DEC/SESC/LLCC, Bât. 352, 13108 Saint-Paul-Lez-Durance Cedex, France

${ }^{3}$ CEA Cadarache, DEN, DER, SPRC, LECy, Bât. 230, 13108 Saint-Paul-Lez-Durance Cedex, France

${ }^{4}$ LEEL, NIMBE, CEA, CNRS, Université Paris-Saclay, CEA Saclay 91191 Gif sur Yvette Cedex, France

\section{Keywords}

Oxycarbides; chemical analysis; light elements; Ion Beam Analysis; Nuclear Reaction Analysis

Corresponding author: Gilles Trolliard

Tel.: $\quad+33587502381$

E-mail: $\quad$ gilles.trolliard@unilim.fr 


\section{Abstract}

Pure powders of $\mathrm{TiC}_{\mathrm{x}} \mathrm{O}_{(1-\mathrm{x})}$ solid solution were synthesized through the carbothermal route. The chemical analysis of the light elements in the as-obtained $\operatorname{TiC}_{\mathrm{x}} \mathrm{O}_{(1-\mathrm{x})}$ oxycarbides powders were performed by Instrumented Gas Analysis (IGA). The cell parameters of the samples were determined with an accuracy of about $2 \%$ by means of X-ray powder diffraction and the internal standard method. As a result, a model correlating the cell parameters to the chemical composition was established. These reference $\mathrm{TiC}_{\mathrm{x}} \mathrm{O}_{(1-\mathrm{x})}$ oxycarbides powders were then sintered in order to obtain pellets of dense ceramics. After having determined that the sintering process does not change the chemical composition of the starting powder, chemical analysis of the different samples of the solid solution were successfully undertaken by Ion Beam Analysis techniques (IBA). The Nuclear Reaction Analysis (NRA) method - that was used to analyse light elements with very high sensitivity - was coupled with Rutherford Back Scattering (RBS) analysis in order to accurately determine the metallic over light elements ratio and to determine the stoichiometry of the phase on massive samples. Exhaustive simulations of the NRA spectra were performed and demonstrated that discrete compositions of the $\operatorname{TiC}_{\mathrm{x}} \mathrm{O}_{(1-\mathrm{x})}$ can be efficiently measured locally for bulk samples. Compared to IGA results, the relative amounts of carbon and oxygen of bulk materials were determined with a bias lower than 5\%. This protocol being implemented for the $\mathrm{TiC}_{\mathrm{x}} \mathrm{O}_{(1-\mathrm{x})}$ system was then tested on $\mathrm{HfC}_{\mathrm{x}} \mathrm{O}_{(1-\mathrm{x})}$ with the same success. 


\section{Introduction}

The quantitative analysis of light elements remains one of the ongoing issues in the field of ceramic materials. As an example, this topic is commonly a pending issue for searchers working in the field of carbide based ceramics as carbo-nitrides $\left(\mathrm{MC}_{\mathrm{x}} \mathrm{N}_{\mathrm{y}}\right.$ : $\left.\mathrm{M}=\mathrm{Si}, \mathrm{Ti}, \mathrm{Zr}, \mathrm{Hf} \ldots\right)$ or oxycarbides $\left(\mathrm{MC}_{\mathrm{x}} \mathrm{O}_{\mathrm{y}}\right)$ for which macroscopical properties depend strongly on their respective amounts of light elements [1]. In the present paper, we report and compare different investigation techniques aiming at characterizing directly or indirectly the chemical composition of both powders and bulk samples of $\mathrm{MC}_{\mathrm{x}} \mathrm{O}_{\mathrm{y}}$ oxycarbides compounds.

The oxycarbide is a frequently encountered compound. Indeed, as the most used route to elaborate carbides, the carbothermal reduction reaction which consists in the progressive reduction of dioxides with carbon generally leads to an oxycarbide final product [2-4] whose composition is largely dependent on the synthesis conditions. Besides, these ultrarefractory carbides are ideally suited for ultra-high temperature applications [5], thanks to their favorable properties: high hardness, good wear resistance and high decomposition temperature [6]. These properties allow them to be used for example as barriers retaining the fission products in nuclear reactors [7], or as wear-resistant coatings [8]. However, the application field of zirconium carbide is limited under air due to its low oxidation resistance [9]. As a consequence, they are progressively transformed into oxycarbides during their use through carbon-oxygen substitution [10-12]. Therefore, the accurate quantification of light elements ( $\mathrm{C}$ and $\mathrm{O})$ in heavier matrices is a topic of significant interest in order to define the actual stoichiometry of the studied oxycarbides and to connect these compositions to their expected properties.

The analysis of oxycarbides meets two different kinds of issues depending on whether the sample is a powder or a bulk-type ceramics. When assuming homogeneous samples, powders are generally characterized by coupling X-ray powder diffraction (XRD) and X-Ray Fluorescence (XRF) or Instrumented Gas Analysis (IGA), which provide information averaged 
over macroscopic sample volumes only. This is for example the case with commercial powders that are mostly considered as homogeneous starting raw materials. The case of bulk type carbide ceramics is, however, more complicated. The high hardness of bulk type carbide materials makes complicated their quantitative analysis because the crushing of ceramics can lead to the incorporation of some impurities. In addition these samples are most often encountered under the form of composite materials and in this case, the global techniques of chemical analysis by IGA or XRF are no longer valid as they will solely provide an average analysis of the sample. For these reasons, numerous fields of research on ceramics could, however, take advantage of analytical methods allowing to perform accurate quantitative analysis of light element at local scale (micrometer to nanometer scale). In this paper, the Nuclear Reaction Analysis (NRA) method was used on bulk type oxycarbides to locally analyse light elements such as carbon and oxygen with very high sensitivity in transition metal oxycarbides of the IVb-group. NRA was associated with Rutherford Back Scattering (RBS) analysis which gives the ratio of metallic over light elements and makes it possible to determine the phase stoichiometry with good accuracy.

Concerning the choice of the chemical system, the focus was set on $\mathrm{TiO}_{2}-\mathrm{C}$. Indeed, the stability domain of the $\mathrm{TiC}_{\mathrm{x}} \mathrm{O}_{\mathrm{y}}$ solid solution has already been investigated in the literature and it has been shown that the solid solution was complete between $\mathrm{TiC}$ and $\mathrm{TiO},[13,14]$ giving rise to a wide compositional range of $\mathrm{TiC}_{\mathrm{x}} \mathrm{O}_{\mathrm{y}}$ compounds. This chemical system was also retained because some of the authors of this publication share a long standing experience in synthesis and characterisation of these compounds $[3,15,16]$. In the present study, the synthesis of the starting powders was achieved through the carbothermal reduction of $\mathrm{TiO}_{2}$ by carbon black [3]. After having controlled the phase and purity of each synthesized powder sample by XRD and Transmission Electron Microscopy (TEM) and their chemical composition by Instrumented Gas Analysis (IGA) with an accuracy of a few atomic percent, the high purity 
powders obtained were considered as reference materials to test the accuracy of the Ion Beam Analysis techniques (IBA) on bulk samples that were obtained from the powders.

The first part of this paper is devoted to the establishment of a model that can be further on used by the readers to correlate the evolution of the cell parameter of the solid solution with the oxygen and carbon content. In this part, a special attention has been paid to accurately determine the cell parameters by minimizing systematic errors related to X-ray powder diffraction measurements. In the past, several models linking the oxycarbide cell parameter with its chemical composition had already been proposed in the literature $[13,14,17]$. However, none of these works used an internal standard to correct for sample positioning errors, which results in large uncertainties in the measurement of the cell parameters. In addition, in none of these previous works the targeted compositions were checked by elemental analysis, so that the mentioned compositions are not fully reliable.

The second part of the paper deals with the local analysis of bulk ceramic materials by IBA. In this work, bulk oxycarbides sintered by Spark Plasma Sintering (SPS) from well controlled powders are used as references in order to evaluate IBA capabilities for light elements quantification in ceramics. The expected results were first simulated and discussed and the obtained results were then compared to those obtained by IGA on powder samples. The methodology was first implemented on $\mathrm{TiC}_{\mathrm{x}} \mathrm{O}_{\mathrm{y}}$ and was further on applied to an $\mathrm{HfC}_{\mathrm{x}} \mathrm{O}_{\mathrm{y}}$ sample.

\section{Synthesis of powders and SPS sintering of bulk samples}

\subsection{Synthesis and characterization of powders}

The synthesis protocol of powders was described in a previous paper [3]. Summarily, $\mathrm{TiO}_{2}$ powder (99.9\% wt.\%, Anatase, Alfa Aesar) and carbon black (Prolabo, France, ashes < $0.75 \%$ 
wt.\%) were weighted to the desired final composition of oxycarbide according to the global reaction:

$$
\mathrm{TiO}_{2(\mathrm{~s})}+(1+2 \mathrm{x}) \mathrm{C}_{(\mathrm{s})} \rightleftarrows \mathrm{TiC}_{\mathrm{x}} \mathrm{O}_{1-\mathrm{x}(\mathrm{s})}+(1+\mathrm{x}) \mathrm{CO}_{(\mathrm{g})}
$$

The theoretical targeted compositions were calculated assuming that the sum of the C/Ti and $\mathrm{O} / \mathrm{Ti}$ ratios is equal to 1 . In such a condition the amount of possible vacancies is neglected and in the following the general formulae of the oxycarbide will be written as $\operatorname{TiC}_{\mathrm{x}} \mathrm{O}_{(1-\mathrm{x})}$. Eight different samples with theoretical formulae were synthesized (Table 1) and two sets of samples were performed: one at $1500^{\circ} \mathrm{C}$ and the other at $1600^{\circ} \mathrm{C}$. The initial powders of carbon black and titanium dioxide were mixed in various proportions using a low speed planetary ball mill (Pulverisette 7, Fritsch, Germany). The blending sequence was composed of 5 pulses of 1 min at $200 \mathrm{rpm}$ interrupted by pauses of $5 \mathrm{~min}$ to avoid heating up the materials. Each mixture was then treated for $4 \mathrm{~h}$ in a graphite furnace (V.A.S. furnace, Suresnes, France) under flowing

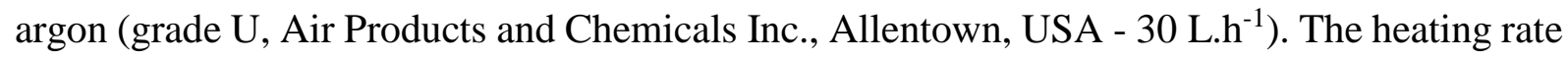
was fixed at $20^{\circ} \mathrm{C} \cdot \mathrm{min}^{-1}$ up to the targeted temperatures $\left(1500^{\circ} \mathrm{C}\right.$ or $\left.1600^{\circ} \mathrm{C}\right)$. The sample was then maintained 4 hours in temperature in order to reach the maximal extent of the reaction $(\xi=1)$ as previously defined in ref. [3]. Oxygen richest compositions were more difficult to obtain as pure powders so that $\mathrm{TiC}_{0.40} \mathrm{O}_{0.60}, \mathrm{TiC}_{0.30} \mathrm{O}_{0.70}$ and $\mathrm{TiC}_{0.20} \mathrm{O}_{0.80}$ samples required two complete runs of heating treatment as specified in table 1 in order to reach the maximal advancement of the reaction $(\xi=1)$. Between heating treatments, the powders were homogenized by crushing in an agate mortar.

Finally and as an extension of this study, powder samples of $\mathrm{HfC}_{0.85} \mathrm{O}_{0.15}$ were synthesized (Table 1) to elaborate bulk ceramics to check the methodology implemented on $\mathrm{TiC}_{\mathrm{x}} \mathrm{O}_{(1-\mathrm{x})}$. In a second step, this system will allow to test the relevance of the IBA technique for quantitative analysis of light elements in other oxycarbides showing contrasted $\mathrm{Z}$ values. 


\subsection{Shaping of pellet-type bulk materials and comparison with powders}

With regards to their high melting point and their related low self-diffusion, the complete densification of carbides powders requires extremely high sintering temperature [18]. In such conditions, high relative densities of samples are usually obtained by using pressureassisted sintering methods (Hot Isostatic Pressing or Hot Pressing). Fully dense samples are then obtained at very high temperature and/or by using sintering aids such as metallic elements [19]. As a consequence of the high temperature used, the microstructures of the samples so obtained are generally coarse and contain noticeable residual porosity. In this context, the Spark Plasma Sintering (SPS) represents one possible way to densify ceramic materials, keeping fine microstructures (i.e. microsized) without sintering additives even for poorly sinterable compounds [20,21]. According to the SPS procedure, the raw powders are firstly put into a graphite die before being uniaxially pressed while a D.C. pulse voltage is applied to the compact. In the case of electrically conductive materials, the heating-up is then mainly due to the Joule effect. Compared to hot-pressing, the SPS technique allows sintering at lower temperatures and shorter soaking times, even for high refractory ceramics such as zirconium carbide-based materials [22]. The oxycarbide powders were placed into a graphite matrix for SPS treatments. Bulk dense $20 \mathrm{~mm}$ diameter pellets (95\% of the theoretical density) were sintered at $1600^{\circ} \mathrm{C}$ and $50 \mathrm{MPa}$ under vacuum during 10 minutes. This process was applied to the synthesis of the richest five compositions in carbon (Table 1).

As the IGA analysis results obtained on the powder samples will be used as standards for the IBA analysis of sintered bulk specimens, it is necessary to make sure that the sintering process did not modify the composition of the sample. It has been previously shown that slight substitution of carbon atoms by oxygen atoms leads to a significant decrease in the cell parameter, the covalent radius of oxygen $\left(r_{O}=0.64 \AA\right)$ being lower than that of carbon $\left(r_{C}=\right.$ $0.74 \AA$ ) $[2-4,23,24]$. A small change of the cell parameter induces in turn peak shifts in the 
XRD patterns, the peaks typically shifting towards high $2 \theta$ angles as the oxygen content increases within the oxycarbide.

Figure 1a shows the XRD patterns of a synthesized powder and its corresponding bulk monolith shaped by SPS (theoretical composition: $\mathrm{TiC}_{0.90} \mathrm{O}_{0.10}$ ). In both cases, the XRD patterns indicate that pure single phase samples were obtained as compared to international diffraction data card PDF-ICDD 00-032-1283 [25]. In addition, the peak positions of the two samples are very close, as shown by the enlargement of the 422 diffraction peak in Fig. 1(b). The slight shift corresponds to a cell parameter change of less than $0.004 \AA$. This difference in cell parameters typically corresponds to a compositional change of less than $1 \%$, i.e. lower than the error of the chemical analysis. It is therefore possible to consider that the stoichiometry of the oxycarbide phase is not modified during the SPS treatment. All synthesized pellet compositions were tested by the protocol presented above and in the following, we shall therefore consider that IGA analysis carried out on powders can be compared to the bulk sample analysis by IBA.

It is also worth mentioning that the line widths of the powder samples, as an example $0.08^{\circ} \mathrm{FWHM}$ for the 422 peak, are close to the instrumental resolution function. This result attests of a very homogeneous composition within the powder grains. All of these controls were performed on each sample of the different synthesised compositions.

\section{Experimental}

\subsection{XRD and TEM analyses}

Cell parameters measurements were performed using X-ray powder diffraction (XRD) and the Rietveld method. The XRD patterns of all the samples were collected from 10 to $125^{\circ}(2 \theta)$ with $\mathrm{CuK} \alpha_{1}$ radiation using a Bruker D8 Advance diffractometer (Karlsruhe, Germany) with BraggBrentano geometry, LynxEye PSD detector and Ge (111) primary monochromator. A step size of $0.02^{\circ}(2 \theta)$ and an effective acquisition time of 208 s per step were chosen to get data with 
well-defined peaks and good counting statistics. In order to further minimize errors affecting the cell parameter values, an internal standard was used to correct for sample positioning errors. It is well known that, even with careful sample preparation, sample positioning can be the major source of peak position errors and can vary significantly from one sample to another. Among the possible standard materials, alumina $\left(\mathrm{Al}_{2} \mathrm{O}_{3}\right)$ with corundum structure was found to be a good candidate as it allowed minimizing overlap between the standard and sample peaks. For practical reasons, we decided not to use the standard reference material from NIST (SRM676a) but instead the $\mathrm{Al}_{2} \mathrm{O}_{3} 4 \mathrm{~N}$ (99.99\%) from Baikowski. This corundum of high purity is indeed easily available at low cost and allowed obtaining good quality XRD reference patterns with measured cell parameters close (within $0.0005 \AA$ ) to that of the certified NIST values. It was slightly cleaned by heat treatment at $900^{\circ} \mathrm{C}$ during 1 hour (weight loss of $0.4 \%$ ) before being mixed to the oxycarbide sample powders with a weight ratio of $50 \%$. The lattice parameters were refined by the Le Bail method using the Fullprof software [26].

In order to detect the possible presence of residues of free carbon, Transmission Electron Microscopy (TEM) characterizations were performed on the powder sample. Observations were carried out with a JEOL 2010 and a TEM-STEM JEOL 2100 microscope (JEOL, Tokyo, Japan) operating at $200 \mathrm{kV}$. TEM samples were obtained by crushing powders in an agate mortar with water. A small drop containing some grains was deposited on a copper grid covered by holey carbon film.

\subsection{Chemical analysis by IGA and IBA}

IGA (Instrumental Gas Analysis) is a common method for $\mathrm{C} / \mathrm{S}$ and $\mathrm{H} / \mathrm{O} / \mathrm{N}$ determination from combustion gases, routinely used in the industry and laboratories.

For carbon content determination, the sample is melted in a preheated ceramic aluminabased crucible using a high-frequency induction furnace in a pure oxygen atmosphere, leading 
carbon to react with oxygen to form carbon monoxide and carbon dioxide. For high temperature refractories, accelerators and fluxes are commonly used to decrease the melting temperature and to maintain the melt thoroughly fluid. In this work, high purity (>99.95 wt.\%) copper, iron and tin chips were used. The combustion gases pass through a dust filter coupled with a moisture absorber for purification. The $\mathrm{C}$ content is finally determined using infrared cells settled on specific absorption bands. Standard samples are needed to calibrate the quantification chain.

For the oxygen content determination, the sample is placed in a graphite crucible between two electrodes and melted using a high current impulse furnace. The oxygen contained in the sample reacts with the graphite crucible forming carbon monoxide and carbon dioxide that are extracted by the He carrier gas. The extracted gas is analyzed after passing through the coupled dust filter - moisture absorber system and the oxygen concentration is therefore determined by infrared cells. As for carbon analysis, the quantification of oxygen requires the use of standard samples, accelerators and fluxes ( $\mathrm{Ni}$ capsules in this work). Most of the methodology for carbon and oxygen content determination using IGA is documented in normative documents (ISO 9556 for carbon [27], ISO 17053 for oxygen [28]).

The elemental chemical analyses (IGA) were performed at the 'Institut des Sciences Analytiques' (UMR-CNRS 5280 - Villeurbanne - France). The $\operatorname{TiC}_{\mathrm{x}} \mathrm{O}_{(1-\mathrm{x})}$ samples measured by IGA are characterized by elevated weight percent in C and O (around 20-30 wt.\%).

Handling samples with so large amount of light elements requires limiting the sample mass in order to avoid the detector saturation (infrared detector focused on the $\mathrm{CO}$ absorption band). The detection limit of the used setup is 1ppm (wt.) and the measurement range spreads from $1 \mathrm{ppm}$ up to $\sim 30 \mathrm{wt} \%$ with such adapted samples masses. To prepare samples, melting aids are classically used. Their contribution is systematically removed during calibration.

For IGA analysis, the uncertainty budget could be split in two main contributions. The first one is correlated to the measurement chain (baseline stability, electronic noise, IR-cell 
sensitivity evolution mainly), the second one to the calculation of the carbon or oxygen content based on the weight of the measured sample.

- The measurement chain is calibrated using standard samples and the repeatability uncertainty may be evaluated using the dispersion divided by the square root of the number of measurements. Certified standard compounds are used to calibrate the overall setup. For high $\mathrm{C}$ and $\mathrm{O}$ content, the relative dispersion after calibration is close to 0.5 wt.\% for $\mathrm{O}$ and less than $1 \mathrm{wt} . \%$ for $\mathrm{C}$. The repeatability dispersion is close to the same values than for the calibration step. As calibration inspections on the setup are carried out regularly (each 10 samples classically), errors on the detection chain are in the same range of magnitude as standard compounds used and can then be minimized.

- The weighting of the analyzed samples is then the only possible error source. Manipulations need to be carefully done with a high precision balance $(1 / 10$ or $1 / 100$ mg significant digit). As previously said, the samples masses used for these analyses are low (around $50 \mathrm{mg}$ ) so that this weighting step is crucial. The calculation of the $\mathrm{C}$ and $\mathrm{O}$ concentration is done based on the total mass of samples, this latter being precisely determined.

As a consequence, the uncertainty budget of IGA shows that the relative error is better than 1 wt. \% using IGA for $\mathrm{C}$ and around $0.5 \mathrm{wt}$. \% for oxygen.

Ion Beam Analysis techniques constitute interesting tools because they are sensitive both to heavy and light elements through the simultaneous use of Rutherford Back Scattering (RBS) and Nuclear Reaction Analysis (NRA). When performed on a micrometric scale, and beyond the advantage of being non-destructive methods, they also constitute an ideal tool for composite sintered pieces or for diffusion couples where the spatial extent of coexisting phases is limited [29]. In this work, the microprobe of the CEA/CNRS/IRAMIS/LEEL [30] was used for the study of homogeneous oxycarbide samples based on the experimental conditions 
previously determined by Martin et al. [31]. We used for simultaneous NRA and RBS measurements an incident beam of deuterons $\left({ }^{2} \mathrm{H}^{+}\right)$with an energy of $950 \mathrm{keV}$ providing an analysis depth of circa $2 \mu \mathrm{m}$. The beam spot was $\sim 2 \times 2 \mu \mathrm{m}^{2}$ and was scanned over a $200 \times 200$ $\mu \mathrm{m}^{2}$ area. These choices enable composite materials analysis as already mentioned, as far as distinct phases are $\mu \mathrm{m}$-sized.

The experimental conditions were previously determined by Martin et al. [31] using an incident beam of deuterons $\left({ }^{2} \mathrm{H}^{+}\right)$with an energy of $950 \mathrm{keV}$. In these conditions the crosssections of non-resonant reactions ${ }^{12} \mathrm{C}\left(\mathrm{d}, \mathrm{p}_{0}\right){ }^{13} \mathrm{C},{ }^{16} \mathrm{O}\left(\mathrm{d}, \mathrm{p}_{0}\right){ }^{17} \mathrm{O},{ }^{16} \mathrm{O}\left(\mathrm{d}, \mathrm{p}_{1}\right){ }^{17} \mathrm{O}$ and ${ }^{16} \mathrm{O}\left(\mathrm{d}, \alpha_{0}\right){ }^{14} \mathrm{~N}$ are well-known and are issued from benchmarked evaluations [32]. The signals from RBS and NRA reactions both produced by the deuteron beam were collected by means of a custom made Canberra ${ }^{\circledR}$ detector offering a limited active thickness of $60 \mu \mathrm{m}$ located at $150^{\circ}$ from incident beam. The reduced active thickness of the detector leads to partial energy deposition of protons from the ${ }^{12} \mathrm{C}\left(\mathrm{d}, \mathrm{p}_{0}\right){ }^{13} \mathrm{C}$ whereas alpha from ${ }^{16} \mathrm{O}\left(\mathrm{d}, \alpha_{0}\right){ }^{14} \mathrm{~N}$ are totally stopped. It produces energy spectra where contributions from the different reactions are clearly identified.

The solid angle was close to $200 \mathrm{mSr}$ with a typical beam current of $100-150 \mathrm{pA}$ to keep count rate below $2000 \mathrm{cps}$ and thus avoid pile-up. Integrated charges where in the $1 \mu \mathrm{C}$ range. The secondary electrons were collected by polarizing the sample holder $(+90 \mathrm{~V})$ thus limiting the uncertainty on the measured electrical charge. A layer of silver lacquer was spread over the epoxy resin holding the samples as well as on the sides of the samples in order to establish electrical contact between the samples and the sample holder.

Calibration of the detection chain was carried out using $\mathrm{CaCO}_{3}$.

SIMNRA 6.06 software [33] with standard Ziegler/Biersack stopping powers was used to simulate RBS+NRA spectra and compare them to the experimental ones in order to interpret them quantitatively. To this aim, the in depth homogeneous solid phase to be analysed is considered as a single layer with an elemental composition in Ti, $\mathrm{C}$ and $\mathrm{O}$ to be determined. An 
incident particle with the energy $\mathrm{E}_{0}$ loses its energy according to the composition and stopping power of each element in the compound. Emitted particles along the acquisition direction $\left(\Theta=150^{\circ}\right)$ also lose energy as moving out of the solid phase. The energy losses before and after the reaction induce a spreading of the reaction peaks. Energy loss spreading is caused by the statistical fluctuations of the energy transfer in the collision process. SIMNRA takes into account both electronic and nuclear energy losses. A second cause of straggling is due to the finite size of the beam and the width of the detector aperture. SIMNRA computes spectra with a convolution by a Gaussian, the half-height width of which accounts for these straggling phenomena. The best width in our case was $\sigma=92 \mathrm{keV}$.

Figure 2 displays the RBS+NRA experimental (dots) and simulated spectra (solid lines) of $\mathrm{TiC}_{\mathrm{x}} \mathrm{O}_{(1-\mathrm{x})}$. It shows, at low energy $(\mathrm{E}<\sim 1000 \mathrm{keV})$ the $\mathrm{RBS}$ contribution of the main isotopes of the sample to the spectrum, and at high energy $(1250 \mathrm{keV} \leq \mathrm{E} \leq 2700 \mathrm{keV})$ the NRA contribution of $\mathrm{C}$ and $\mathrm{O}$ isotopes. Simulating the spectra of $\mathrm{TiC}_{\mathrm{x}} \mathrm{O}_{(1-\mathrm{x})}, \mathrm{x}$ ranging from 0.1 through 0.9, we show, in two Regions Of Interest (ROI) of the NRA part of the spectrum (Fig. 3), the contributions of $\mathrm{O}$ only (Fig. 3a) with the peaks due to the energy of both $\alpha$ particles from the reaction ${ }^{16} \mathrm{O}(\mathrm{d}, \alpha){ }^{14} \mathrm{~N}$ and of protons from the reaction ${ }^{16} \mathrm{O}\left(\mathrm{d}, \mathrm{p}_{0}\right){ }^{17} \mathrm{O}(\mathrm{ROI}=[1700 \mathrm{keV}$; $2700 \mathrm{keV}]$ ) and the contribution of both $\mathrm{C}$ and $\mathrm{O}$ through the energy of the protons emitted by the reactions ${ }^{12} \mathrm{C}\left(\mathrm{d}, \mathrm{p}_{0}\right){ }^{13} \mathrm{C}$ and ${ }^{16} \mathrm{O}\left(\mathrm{d}, \mathrm{p}_{1}\right){ }^{17} \mathrm{O}$ (Fig. 3b ROI=[1250 keV; $\left.\left.1700 \mathrm{keV}\right]\right)$. In the $\mathrm{O}$ only ROI, since all contributions come almost from the element $\mathrm{O}$, the background, i.e. the contribution of other elements, is close to zero, which shows that $\mathrm{O}$ concentration can be reached (Fig. 4a). In the $\mathrm{C}+\mathrm{O} \mathrm{ROI}$, the background for $\mathrm{C}$ concentration determination is the ${ }^{16} \mathrm{O}\left(\mathrm{d}, \mathrm{p}_{1}\right){ }^{17} \mathrm{O}$ signal of $\mathrm{O}$ which can be subtracted using the $\mathrm{O}$ only ROI (Fig. 4b). It was then concluded that it is possible to isolate unambiguously $\mathrm{C}$ and $\mathrm{O}$ signals from any $\operatorname{TiC}_{\mathrm{x}} \mathrm{O}_{(1-\mathrm{x})}$ compound (x ranging from 0.1 to 0.9) (Fig. 4). Combined NRA and RBS analysis was already utilized to determine the composition of several light element including some $\mathrm{TiO}$ and $\mathrm{HfO}$ 
based materials, but these works are restricted to the case of thin films $[34,35]$ and were mostly performed using exclusively RBS [36,37]. Moreover, none or very little is discussed about uncertainties. However at first glance, the uncertainty budget should lead to pessimistic conclusions regarding the relevance of IBA technics. Table 2 lists the main expected error sources and indicative values are given. This budget is partly constituted from statistical error (type A), here the collection statistics follows a Poisson law so that its variance in a given channel (denoted ' $\mathrm{i}$ ') is equal to the number of counts in that channel (experimental value ' $\mathrm{T}_{\mathrm{i}}$ ', computed value ' $\mathrm{M}_{\mathrm{i}}$ '). It increases linearly with acquisition time so that the associated relative uncertainty diminishes as $\mathrm{t}^{-1 / 2}$. Budget is also relevant to B-type non-statistical errors. Collected charge and solid angle (respectively B1 and B2 errors in Table 2) can be neglected, as far as one assumes that it is possible to extract from the spectra measurable contributions from all the elements present in the sample, which is indeed the case here based on the simulations presented above (see Fig. 2 and Fig. 3). It should however be noticed that this applies for a single experimental shift. This last condition applies also for the measurement angle contribution (B3 contribution in Table 2). Cross-sections (B4) and stopping power (B5) will constitute unavoidable sources of errors. For RBS, cross-section errors should remain limited (3-5\%), but for NRA, when available, published cross-section errors go up to $10 \%$ (i.e. $6 \%$ for ${ }^{12} \mathrm{C}\left(\mathrm{d}, \mathrm{p}_{0}\right){ }^{13} \mathrm{C}$ [38], $10 \%$ for $\left.{ }^{16} \mathrm{O}\left(\mathrm{d}, \mathrm{p}_{0}\right)^{17} \mathrm{O}[39]\right)$, mainly because of uncertainties originating from the thin film thickness estimate and counting statistics used for cross-section measurements. The stopping power, which evaluates the amount of deposited energy by the incoming (or exiting) beam in/from the sample, is the second major source of error. This parameter is related to the sample composition and is generally calculated using a simplified model based on balanced monoelemental contributions.

However, when we restrict the analysis to one type of composition and after extracting data issued from the same experimental shift, comparative measurements make full sense. 
Additionally, and in order to evaluate at a given acceptability level the uncertainty of fitted parameters (P parameters):

- layer composition,

- energy resolution, detector active thickness common to all spectra,

we used, as complementary software tool, MULTISIMNRA [40] to fit $\mathrm{S}$ spectra with $\mathrm{N}_{\mathrm{S}}$ channels of the same sample. The quantity:

$$
Z=\frac{1}{S} \sum_{S=1}^{S}\left(\frac{1}{N_{S}-P} \sum_{i=1}^{N_{S}} \frac{\left(M_{i}-T_{i}\right)^{2}}{M_{i}}\right)
$$

follows a $\chi^{2}$ law with Ns-P degrees of freedom, i.e. the function of partition of $\mathrm{Z}$ reads :

$$
F\left(N_{S}-P, Z\right)=\frac{\int_{0}^{Z} t^{\frac{N_{S}-P}{2}-1} e^{-t} d t}{\int_{0}^{+\infty} t^{\frac{N_{S}-P}{2}-1} e^{-t} d t}
$$

The best parameters values make $\mathrm{Z}$ minimum. The initial parameters values are those given by MULTISIMNRA user, $\mathrm{Z}$ is computed and parameters values are changed according to a NelderMead simplex algorithm within the limits given by the user until $\chi^{2}$ remains constant or the maximum number of iterations is reached. Every $k$ iteration, a perturbation is applied to the parameters in order to check that the set of parameters is not stuck at a local minimum. Uncertainties upon the fitted parameters are then computed on the basis of a MonteCarlo method. Once the possible interval for fitted parameters and the confidence level (for instance $68.3 \%$, i.e. $\alpha=1-0.683$ of a Gaussian distribution lies in an interval whose half width is $\sigma$ ) are fixed, MULTISIMNRA picks up random values for the parameters and keeps this set of parameters if $\mathrm{Z}$ is such as $F\left(N_{S}-P, Z\right) \leq \alpha$. In our case $\mathrm{N}_{S}=3000$ spectra were computed. Elimination of the $3000 *(1-\alpha / 2)$ smallest and largest values for a parameter in the set gives its confidence interval.

Ideally cross section and stopping power errors should be taken into account by a MonteCarlo method for the simulation of spectra and should appear in the values of $\mathrm{M}_{\mathrm{i}}$ so that 
MULTISIMNRA could account for it in the uncertainties computed for the studied parameters (here composition of the material), but it is not the case. Thus, uncertainties obtained in this study (Table 4) are obtained in the following way. Since the contribution Mi to a spectrum due to the concentration $[\mathrm{X}]$ of an element $\mathrm{X}$ in the material is proportional to $\sigma / \varepsilon$ where $\sigma$ is the cross-section and $\varepsilon$ the corresponding stopping-power, the total uncertainty i.e. that computed by MULTISIMNRA and that due to the cross-section error are added in the following way :

$u([X])^{2}=u_{\text {Multisimnra }}([X])^{2}+\left(\frac{\partial[X]}{\partial \sigma}\right)^{2} u(\sigma)^{2}+\left(\frac{\partial[X]}{\partial \varepsilon}\right)^{2} u(\varepsilon)^{2}$

Which leads to :

$$
u([X])^{2}=u_{\text {Multisimnra }}([X])^{2}+\left(-\frac{[X]_{\text {Multisimnra }}}{\sigma}\right)^{2} u(\sigma)^{2}+\left(\frac{[X]_{\text {Multisimnra }}}{\varepsilon}\right)^{2} u(\varepsilon)^{2}
$$

\section{Results and discussion}

\subsection{Powder samples: establishing a model linking parameter cell versus composition.}

Figure 5 shows the XRD patterns obtained on the titanium oxycarbide samples synthesized at $1600^{\circ} \mathrm{C}$ (Fig. 5). For all compositions, the diffraction peaks correspond to those of the PDF-ICDD 00-032-1283 [25] file of the titanium carbide. On the right hand side of the figure, the enlargements on the 422 diffraction peak emphasize a shift towards high angles when the amount of the oxygen rises in the crystalline structure. For samples with a theoretical C/Ti ratio $>0.50$ a heat treatment of 4 hours was found sufficient to get a single phase product. However, samples with a $\mathrm{C} / \mathrm{Ti}$ ratio $<0.50$ systematically contained a sesquioxide $\mathrm{Ti}_{2} \mathrm{O}_{3}$ secondary phase so they were heat treated a second or a third time in order to reach the final state of the thermodynamic equilibrium. These supplementary heat treatments of four hours at $1600^{\circ} \mathrm{C}$ (see Table 1) caused the disappearance of $\mathrm{Ti}_{2} \mathrm{O}_{3}$ and led to an enrichment of the oxycarbide phase in oxygen. 
The samples have been observed in Transmission Electron Microscropy in order to detect free carbon (Fig. 6). Owing to the low molar mass of carbon, a slight molar excess will correspond to an important volume proportion that will be easily detectable in TEM. In figure 6, crystals appear as dark entities supported by the hollow carbon film overlapping the Copper grid. In order to be comparable, all images are provided at the same magnification. It can be observed that crystallites show rounded shapes and that the crystal size rises from less than $1 \mu \mathrm{m}$ for pure TiC (Fig. 6a) up to several microns for the oxygen richest compositions (Fig. 6 e-i). This increase in crystal size is due to the longer annealing treatments that were used to obtain a uniform chemical composition of the phase and which provoke grain growth. These longer annealing treatments lead to the coalescence of grains (Fig. $6 \mathrm{f}-\mathrm{i}$ ). where the carbon can be easily distinguished as it appears as bright areas due to its low $\mathrm{Z}$ value and related lower absorption). Free carbon has been only observed in the sample with a theoretical composition $\mathrm{TiC}$ (see white circle on the Fig. 6a). Based on these results, the effective chemical compositions of powders can be calculated from the results of Instrumental Gas Analysis (IGA). For the TiC sample, the amount of free carbon has been measured by a partial combustion of the sample and by subtracting this value to the total amount of carbon contained in the sample and the stoichiometry of the sample has been calculated. They are compiled in Table 3. For all the samples, the results obtained by IGA are compared to the calculated stoichiometries. In the worst case, namely for the theoretical composition $\mathrm{TiC}_{0.50} \mathrm{O}_{0.50}$, the gap between this stoichiometry and the effective stoichiometry does not exceed 3 at. \%. As expected, these results confirm that IGA technique appears well suited to characterize powder samples with an accuracy of few atomic percent. These results also confirm that the quality of the powders is reliable enough to be considered as a standard later on.

From the results obtained by XRD, TEM and IGA elemental analysis, it appears that the continuity of the solid solution is confirmed to be complete between the compound $\mathrm{TiC}_{0.97} \mathrm{O}_{0.02}$ 
and $\mathrm{TiC}_{0.21} \mathrm{O}_{0.79}$ at $1600^{\circ} \mathrm{C}$. It is also worth noticing that the same methodology was also adopted to study the extent of the $\operatorname{TiC}_{\mathrm{x}} \mathrm{O}_{(1-\mathrm{x})}$ solid solution at $1500^{\circ} \mathrm{C}$ and the results at this temperature were similar to those obtained at $1600^{\circ} \mathrm{C}$.

Figure 7 shows the evolution of the titanium oxycarbide cell parameter as a function of C/Ti ratio determined by IGA. At first glance, figure 7 shows two distinct parts in which the evolution of the cell parameter can be assumed as linear (see the two dotted lines on Fig. 7).

The positioning of the two linear regression lines was solely calculated based on the experimental points corresponding to the present study. These two distinct tendencies can be interpreted as Vegard type evolutions of two distinct types of solids characterized by different kinds of chemical bond with different related atomic radius. The intersection point between these two lines will then correspond to the composition for which the change in the type of bonding occurs (for $\mathrm{C} / \mathrm{Ti}=0.57$ i.e. for $\mathrm{TiC}_{0.60} \mathrm{O}_{0.40}$ ). As an interpretation, we suggest that an ionic character predominates for the oxygen rich compositions $(\mathrm{C} / \mathrm{Ti}<0.60$, i.e. from $\mathrm{TiO}$ to $\left.\mathrm{TiC}_{0.60} \mathrm{O}_{0.40}\right)$ while a covalent character predominates for the carbon rich compositions in $(\mathrm{C} / \mathrm{Ti}$ $>0.60$, i.e. from $\mathrm{TiC}_{0.60} \mathrm{O}_{0.40}$ to $\left.\mathrm{TiC}_{1-x}\right)$.

The discrepancies existing between our results and the cell parameter values reported from the work of Jiang et al. [14] could be explained by the fact these authors did not use an internal standard to correct samples positioning errors or that their targeted compositions, which highly depend on the synthesis conditions, were not controlled by elemental analysis.

\subsection{Bulk samples: towards reliable analysis of light elements.}

A typical experimental NRA-RBS energy spectrum of $\mathrm{TiC}_{\mathrm{x}} \mathrm{O}_{\mathrm{y}}$ obtained is shown in figure 2 as well as its corresponding spectrum calculated by SIMNRA. All experimental spectra were analysed using first SIMNRA and then MULTISIMNRA software. RBS signals of Ti, C and $\mathrm{O}$ lead to the ratio of light elements $(\mathrm{C}$ and $\mathrm{O})$ over Ti, whereas ${ }^{12} \mathrm{C}\left(\mathrm{d}, \mathrm{p}_{0}\right){ }^{13} \mathrm{C},{ }^{16} \mathrm{O}\left(\mathrm{d}, \mathrm{p}_{1}\right){ }^{17} \mathrm{O}$, 
${ }^{16} \mathrm{O}\left(\mathrm{d}, \alpha_{0}\right){ }^{14} \mathrm{~N}$ and ${ }^{16} \mathrm{O}\left(\mathrm{d}, \mathrm{p}_{0}\right){ }^{17} \mathrm{O}$ led to an enhanced determination of $\mathrm{C} /(\mathrm{C}+\mathrm{O})$ and $\mathrm{O} /(\mathrm{C}+\mathrm{O})$ ratios.

NRA and RBS analysis results obtained on bulk samples are reported in table 4 . The uncertainties were calculated by means of MULTISIMNRA based on the calculation of 3000 spectra leading to a confidence level of $68.3 \%$ [41] (column '*' in Table 4) and also by including standard error contributions as discussed in section 2.2 (column '\#' in Table 4). A very good agreement is found as the discrepancy between them is in the same range of the relative error of IGA analysis. At first sight, it is noticeable that the powder stoichiometries determined by IGA (Table 3) are very similar to the composition of the sintered samples (Table 4) that were obtained by fitting the IBA spectra. By comparing the stoichiometries obtained on light elements with the two techniques, the discrepancy is found to be less than 5 at. $\%$ for all the titanium oxycarbide samples. In addition, for each sample, the amount of Ti calculated from the RBS signal is close to 1 . This observation means that the first sublattice in the f.c.c structure is always fully occupied by Ti atoms. Consequently, the variation of the chemical compositions of the $\mathrm{TiC}_{\mathrm{x}} \mathrm{O}_{(1-\mathrm{x})}$ phases only results from substitution of carbon atoms by oxygen atoms on the second sublattice as shown in the literature [2-4,10,23,24]. Regarding IBA uncertainties budget, and following data from table 2, errors raise to the $10 \%$ range. However the excellent matching between IBA and the much more precise IGA technique central values might be attributed to very conservative values generally used for cross sections and stopping powers uncertainties.

The same global process was finally implemented on a hafnium oxycarbide sample (Table 4). The main difference in MULTISIMNRA simulation consisted in taking into account dual scattering phenomena in order to render a correct RBS signal. The gap between the chemical compositions obtained by IGA and IBA is, here too, close to 5 at. $\%$. 
The relevance of the results obtained for both $\mathrm{TiC}_{\mathrm{x}} \mathrm{O}_{(1-\mathrm{x})}$ and $\mathrm{HfC}_{\mathrm{x}} \mathrm{O}_{(1-\mathrm{x})}$ oxycarbides attests that if present, the density of vacancies on the octahedral site of the oxycarbides is at least almost very low and does not distort the accuracy of the obtained results.

\section{Conclusion and perspectives}

1. Different pure and homogeneous powder samples of $\mathrm{TiC}_{\mathrm{x}} \mathrm{O}_{(1-\mathrm{x})}$ oxycarbides solid solution have been synthesized via the carbothermal route at $1500^{\circ} \mathrm{C}$ and $1600^{\circ} \mathrm{C}$. This study confirms that the solid solution is complete at least in the compositional range $\mathrm{TiC}_{0.97} \mathrm{O}_{0.02} / \mathrm{TiC}_{0.21} \mathrm{O}_{0.79}$

2. Each of the eight synthesized samples were first chemically analysed by IGA with an accuracy of a few atomic percent. The results obtained show that the measured phase stoichiometry is in very good agreement with the expected theoretical synthesized compositions, attesting that the synthesis process is well controlled.

3. Cell parameters of the oxycarbide powders were refined with accuracy better than a few percent in order to establish a reliable model giving the evolution of the cell parameter versus the chemical composition measured by IGA. This model allows an indirect characterization of the $\mathrm{O} / \mathrm{C}$ ratio of the oxycarbide based on a careful determination of the cell parameter through XRD experiments available in most laboratories.

4. The evolution of the cell parameter shows two distinct linear tendencies, of Vegard's law type, attributed to a prevailing ionic character chemical bonds for the oxygen rich compositions $\left(\mathrm{C} / \mathrm{Ti}<0.60\right.$, i.e. from $\mathrm{TiO}$ to $\left.\mathrm{TiC}_{0.60} \mathrm{O}_{0.40}\right)$ and to a covalent character for the carbon rich compositions in $\left(\mathrm{C} / \mathrm{Ti}>0.60\right.$, i.e. from $\mathrm{TiC}_{0.60} \mathrm{O}_{0.40}$ to $\left.\mathrm{TiC}_{1-\mathrm{x}}\right)$.

5. The powder samples were sintered by SPS to obtain $\mathrm{TiC}_{\mathrm{x}} \mathrm{O}_{(1-\mathrm{x})}$ ceramics and were used as standards to evaluate the IBA capabilities to quantify light elements on bulk type 
materials. The results obtained by this technique on the densified monoliths are at least as accurate as those obtained by IGA and confirm that IBA is a well suited method to quantify the light elements amount in bulk materials with very good accuracy.

Evoking micro-IBA, this remarkable result opens a new investigation field for oxycarbide studies and in particular for the understanding of reactive carbide-oxide interfaces for which the determination of light elements concentration profile is required to ascertain the reaction mechanism operating.

Acknowledgements: The authors are grateful to the French GdR CNRS 3584 called Thermodynamique des Matériaux à Haute Température (TherMatHT) for the support and the opportunity to collaborate on this particular topic. All authors are also very grateful to the two referees who made excellent comments and remarks to improve the quality of the article. 


\section{References}

[1] M. Gendre, A. Maître, G. Trolliard, Synthesis of zirconium oxycarbide (ZrCxOy) powders: Influence of stoichiometry on densification kinetics during spark plasma sintering and on mechanical properties, J. Eur. Ceram. Soc. 31 (2011) 2377-2385.

[2] J. David, G. Trolliard, M. Gendre, A. Maître, TEM study of the reaction mechanisms involved in the carbothermal reduction of zirconia, J. Eur. Ceram. Soc. 33 (2013) 165-179.

[3] J. David, G. Trolliard, A. Maître, Transmission electron microscopy study of the reaction mechanisms involved in the carbothermal reduction of anatase, Acta Mater. 61 (2013) 54145428.

[4] F. Réjasse, G. Trolliard, O. Rapaud, A. Maître, J. David, TEM study of the reaction mechanisms involved in the carbothermal reduction of hafnia, RSC Adv. 5 (2015) 45341-45350.

[5] E. Wuchina, E. Opila, M. Opeka, W. Fahrenholtz, I. Talmy, UHTCs: Ultra-High Temperature Ceramic Materials for Extreme Environment Applications, Electrochem. Soc. Interface. (2007) 30-36.

[6] H.O. Pierson, Handbook of Refractory Carbides and Nitrides: Properties, Characteristics, Processing and Applications, William Andrew, 1996.

[7] Y. Katoh, G. Vasudevamurthy, T. Nozawa, L.L. Snead, Properties of zirconium carbide for nuclear fuel applications, J. Nucl. Mater. 441 (2013) 718-742.

[8] Ö.N. Doğan, J.A. Hawk, J.H. Tylczak, R.D. Wilson, R.D. Govier, Wear of titanium carbide reinforced metal matrix composites, Wear. 225-229 (1999) 758-769.

[9] M.M. Opeka, I.G. Talmy, E.J. Wuchina, J.A. Zaykoski, S.J. Causey, Mechanical, Thermal, and Oxidation Properties of Refractory Hafnium and zirconium Compounds, J. Eur. Ceram. Soc. 19 (1999) 2405-2414.

[10] I.L. Shabalin, V.M. Vishnyakov, D.J. Bull, S.G. Keens, L.F. Yamshchikov, L.I. Shabalin, Initial stages of oxidation of near-stoichiometric titanium carbide at low oxygen pressures, J. Alloys Compd. 472 (2009) 373-377.

[11] S. Shimada, A thermoanalytical study of oxidation of TiC by simultaneous TGA-DTA-MS analysis, J. Mater. Sci. 31 (1996) 673-677.

[12] R.F. Voitovich, É.A. Pugach, High-temperature oxidation of titanium carbide, Sov. Powder Metall. Met. Ceram. 11 (1972) 132-136.

[13] H. Nishimura, H. Kimura, On the equilibrium diagram of Titanium-Oxygen-Carbon System, Jpn. Inst. Met. (1956) 589-592.

[14] B. Jiang, N. Hou, S. Huang, G. Zhou, J. Hou, Z. Cao, H. Zhu, Structural studies of TiC1-xOx solid solution by Rietveld refinement and first-principles calculations, J. Solid State Chem. 204 (2013) 1-8.

[15] A. Maitre, D. Tetard, P. Lefort, Role of some technological parameters during carburizing titanium dioxide, J. Eur. Ceram. Soc. 20 (2000) 15-22.

[16] P. Lefort, A. Maitre, P. Tristant, Influence of the grain size on the reactivity of TiO2/C mixtures, J. Alloys Compd. 302 (2000) 287-298.

[17] G. Neumann, R. Kieffer, P. Ettmayer, Über das System TiC-TiN-TiO, Monatshefte Für Chem. Chem. Mon. 103 (1972) 1130-1137.

[18] V.P. Bulychev, R.A. Andrievskii, L.B. Nezhevenko, The sintering of zirconium carbide, Sov. Powder Metall. Met. Ceram. 16 (1977) 273-276.

[19] K.H. Kim, K.B. Shim, The effect of lanthanum on the fabrication of ZrB2-ZrC composites by spark plasma sintering, Mater. Charact. 50 (2003) 31-37.

[20] L. Gao, H. Miyamoto, Spark Plasma Sintering Technology, J. Inorg Mat. (1997) 129-133.

[21] M. Tokita, Trends in Advanced SPS Spark Plasma Sintering Systems and Technology, J. Soc. Powder Technol. Jpn. 30 (1993) 790-804.

[22] F. Goutier, G. Trolliard, S. Valette, A. Maître, C. Estournes, Role of impurities on the spark plasma sintering of ZrCx-ZrB2 composites, J. Eur. Ceram. Soc. 28 (2008) 671-678. 
[23] F. Réjasse, O. Rapaud, G. Trolliard, O. Masson, A. Maître, Experimental investigation and thermodynamic evaluation of the C-O-Zr ternary system, RSC Adv. 6 (2016) 100122-100135.

[24] F. Réjasse, O. Rapaud, G. Trolliard, O. Masson, A. Maitre, Experimental investigation and thermodynamic evaluation of the C-Hf-O ternary system - Réjasse - 2017 - Journal of the American Ceramic Society - Wiley Online Library, J. Am. Ceram. Soc. 100 (2017) 3757-3770.

[25] ICDD (2010). PDF-4+ 2010 (Database), edited by Dr. Soorya Kabekkodu, International Centre for Diffraction Data, Newtown Square, PA, USA.

[26] J. Rodríguez-Carvajal, Recent advances in magnetic structure determination by neutron powder diffraction, Phys. B Condens. Matter. 192 (1993) 55-69.

[27] ISO 9556: https://www.iso.org/standard/17302.html.

[28] F ISO 17053: https://www.iso.org/standard/39763.html.

[29] F. Réjasse, G. Trolliard, J. Léchelle, O. Rapaud, P. Carles, O. Grauby, H. Khodja, Study of the TiC1X - TiO2 reactive interface, Acta Mater. 146 (2018) 225-236.

[30] H. Khodja, E. Berthoumieux, L. Daudin, J.-P. Gallien, The Pierre Süe Laboratory nuclear microprobe as a multi-disciplinary analysis tool, Nucl. Instrum. Methods Phys. Res. Sect. B Beam Interact. Mater. At. 181 (2001) 83-86.

[31] G. Martin, G. Raveu, P. Garcia, G. Carlot, H. Khodja, I. Vickridge, M.F. Barthe, T. Sauvage, Quantitative ion beam analysis of $\mathrm{M}-\mathrm{C}-\mathrm{O}$ systems: application to an oxidized uranium carbide sample, Philos. Mag. 94 (2014) 1177-1191.

[32] A.F. Gurbich, SigmaCalc recent development and present status of the evaluated cross-sections for IBA, Nucl. Instrum. Methods Phys. Res. Sect. B Beam Interact. Mater. At. 371 (2016) 27-32.

[33] M. Mayer, SIMNRA user's guide, 1997. http://home.rzg.mpg.de/ mam/Manual.pdf.

[34] W.A. Lanford, M. Parenti, B.J. Nordell, M.M. Paquette, A.N. Caruso, M. Mäntymäki, J. Hämäläinen, M. Ritala, K.B. Klepper, V. Miikkulainen, O. Nilsen, W. Tenhaeff, N. Dudney, D. Koh, S.K. Banerjee, E. Mays, J. Bielefeld, S.W. King, Nuclear reaction analysis for H, Li, Be, B, C, N, O and $\mathrm{F}$ with an RBS check, Nucl. Instrum. Methods Phys. Res. Sect. B Beam Interact. Mater. At. 371 (2016) 211-215.

[35] J.T. Gaskins, P.E. Hopkins, D.R. Merrill, S.R. Bauers, E. Hadland, D.C. Johnson, D. Koh, J.H. Yum, S. Banerjee, B.J. Nordell, M.M. Paquette, A.N. Caruso, W.A. Lanford, P. Henry, L. Ross, H. Li, L. $\mathrm{Li}, \mathrm{M}$. French, A.M. Rudolph, S.W. King, Review-Investigation and Review of the Thermal, Mechanical, Electrical, Optical, and Structural Properties of Atomic Layer Deposited High-k Dielectrics: Beryllium Oxide, Aluminum Oxide, Hafnium Oxide, and Aluminum Nitride, ECS J. Solid State Sci. Technol. 6 (2017) N189-N208.

[36] A.C. Fernandes, F. Vaz, L. Rebouta, A. Pinto, E. Alves, N.M.G. Parreira, P. Goudeau, E. Le Bourhis, J.P. Rivière, Influence of the $\mathrm{O} / \mathrm{C}$ ratio in the behaviour of TiCxOy thin films, Surf. Coat. Technol. 201 (2007) 5587-5591.

[37] D.A. Pejaković, J. Marschall, M.R. George, B.R. Rogers, W.R. Nieveen, V. Pajcini, Synthesis of carbon-rich hafnia thin films by pulsed laser deposition, J. Eur. Ceram. Soc. 30 (2010) 22892300.

[38] M. Kokkoris, P. Misaelides, S. Kossionides, C. Zarkadas, A. Lagoyannis, R. Vlastou, C.T. Papadopoulos, A. Kontos, A detailed study of the $12 \mathrm{C}(\mathrm{d}, \mathrm{p} 0) 13 \mathrm{C}$ reaction at detector angles between $135^{\circ}$ and $170^{\circ}$, for the energy range Ed,lab=900-2000keV, Nucl. Instrum. Methods Phys. Res. Sect. B Beam Interact. Mater. At. 249 (2006) 77-80.

[39] H. Rafi-kheiri, O. Kakuee, M. Lamehi-Rachti, Differential cross section measurement of $160(d, p 0,1)$ reactions at energies and angles relevant to NRA, Nucl. Instrum. Methods Phys. Res. Sect. B Beam Interact. Mater. At. 371 (2016) 46-49.

[40] T.F. Silva, C.L. Rodrigues, M. Mayer, M.V. Moro, G.F. Trindade, F.R. Aguirre, N. Added, M.A. Rizzutto, M.H. Tabacniks, MultiSIMNRA: A computational tool for self-consistent ion beam analysis using SIMNRA, Nucl. Instrum. Methods Phys. Res. Sect. B Beam Interact. Mater. At. 371 (2016) 86-89.

[41] M. Désenfant, N. Fischer, B. Blanquart, Évaluation de l'incertitude en utilisant les simulations de Monte Carlo, in: Lille, 2007. 


\section{Figure Captions}

Figure 1: Comparison between $\mathrm{X}$-ray diffraction patterns respectively obtained on the synthesized powder and the shaped monolith (theoretical composition: $\left.\mathrm{TiC}_{0.90} \mathrm{O}_{0.10}\right)$.

Figure 2: $\quad$ RBS and NRA spectra for the $\mathrm{TiC}_{0.90} \mathrm{O}_{0.10}$ sample showing the experimental curves (symbols) and the simulated signal (continuous line).

Figure 3: $\quad$ Simulated spectra carried out with the experimental conditions retained during this study. It is shown that NRA is sensitive enough to discriminate all chemical compositions of the titanium oxycarbides.

Figure 4: Model of integrated peak intensity over the ROI versus $\mathrm{C} /(\mathrm{C}+\mathrm{O})$ after background subtraction (in red colour) for $\mathrm{C}$ and $\mathrm{O}$ elements.

Figure 5: X-ray diffraction patterns obtained on the synthesized oxycarbide samples at $1600^{\circ} \mathrm{C}$.

Figure 6: $\quad$ TEM images of each sample synthesized at $1600^{\circ} \mathrm{C}$. The white circle testifies that free carbon is observed in the sample with the $\mathrm{TiC}$ theoretical composition.

Figure 7: Evolution of the titanium oxycabide cell parameter as a function of C/Ti ratio. The measured values by Neumann et al. [17], Nishimura et $a l$. [13] and Jiang and $a l$. [14] have been added in order compare them. 


\section{Table Captions}

Table 1: The chemical formulae of the different $\mathrm{TiC}_{\mathrm{x}} \mathrm{O}_{\mathrm{y}}$ and $\mathrm{HfC}_{\mathrm{x}} \mathrm{O}_{\mathrm{y}}$ samples that were synthesized and their respective theoretical C-O contents. The table also mentioned the temperatures of synthesis and the dwell time. The presence or absence of a cross respectively indicates if the sample has been synthesized or not. On the right side, the SPS conditions have been indicated for each shaped monolith.

Table 2: $\quad$ Non-statistical sources of errors in the IBA technique

Table 3: $\quad$ Results of the elemental analyses (IGA) for the different samples of oxycarbides synthesized at $1600^{\circ} \mathrm{C}$.

Table 4: $\quad$ Results of the IGA and IBA analyses obtained on the synthesized oxycarbide samples with uncertainties for RBS+NRA measurements (*: MultiSIMNRA uncertainties only, \#: combined MultiSIMNRA and standard uncertainties) 


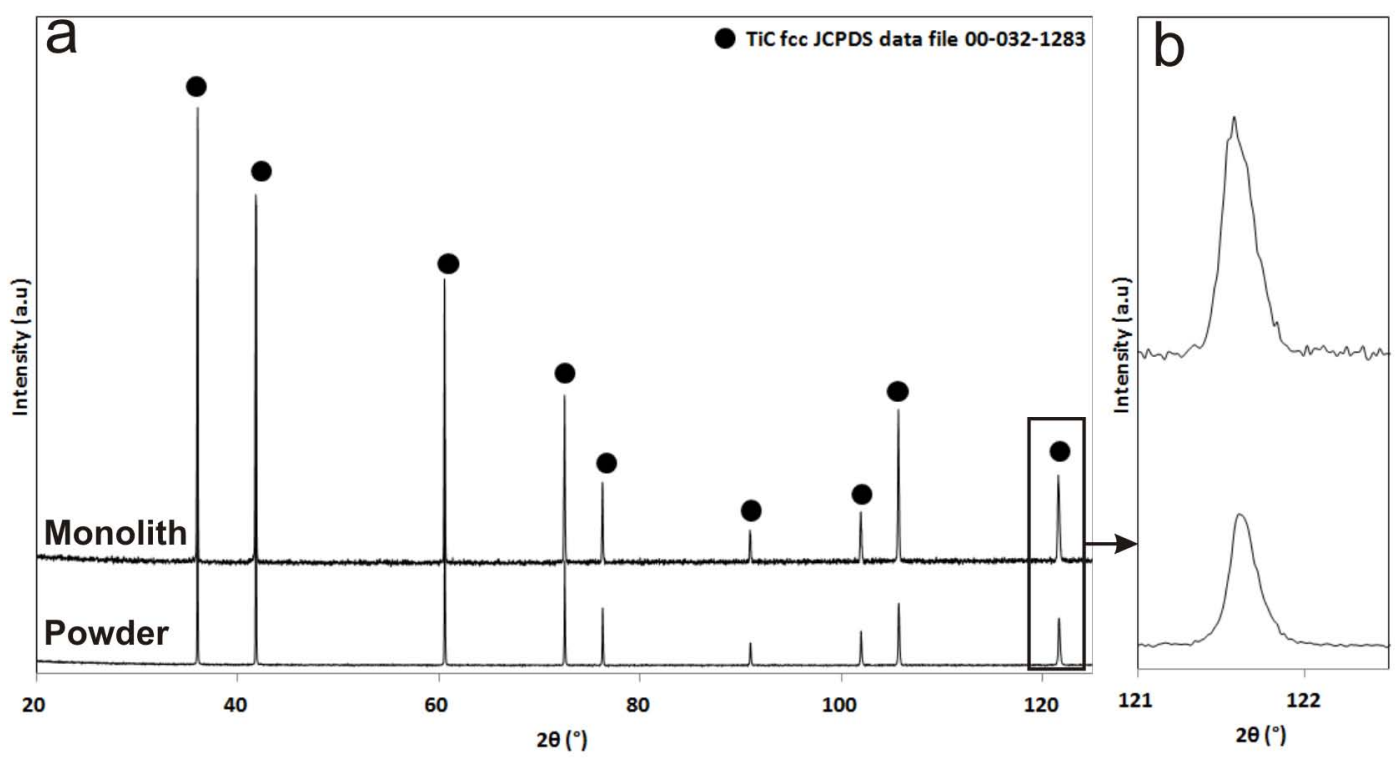




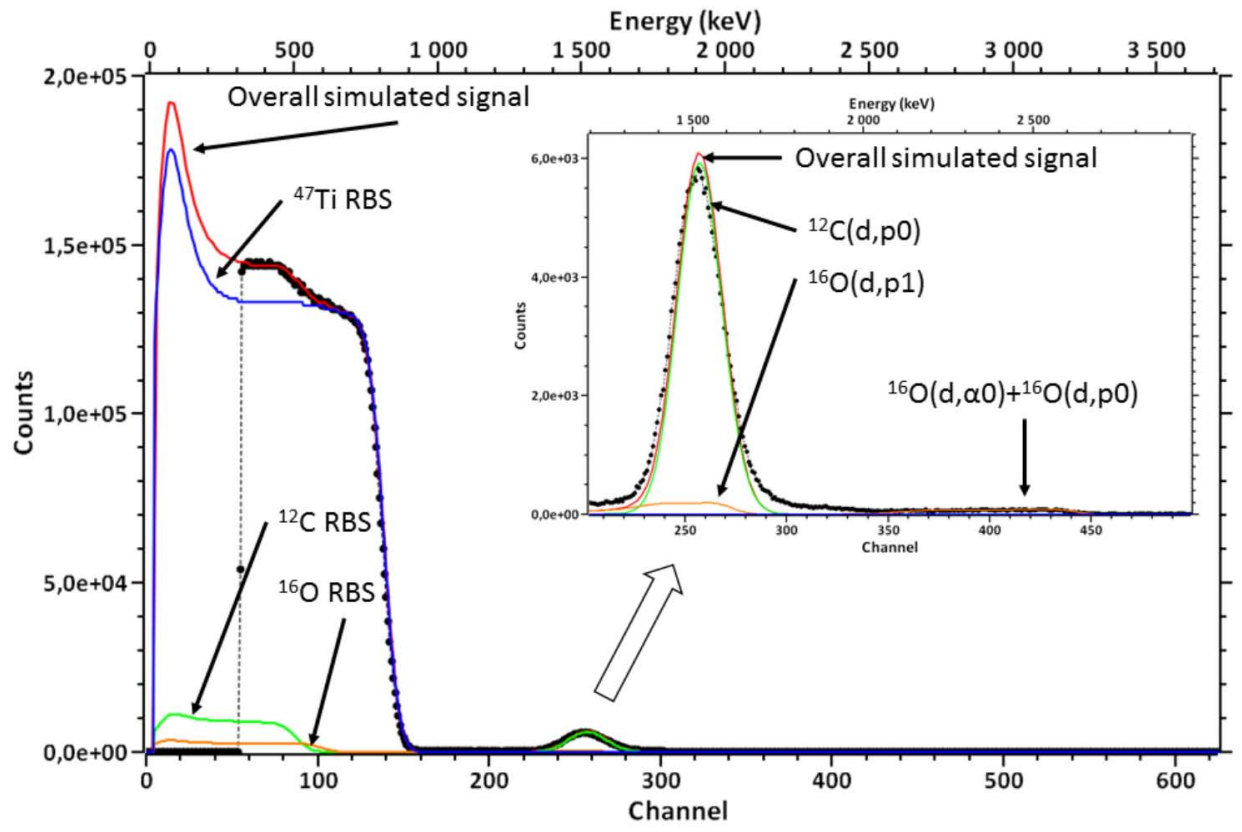


a

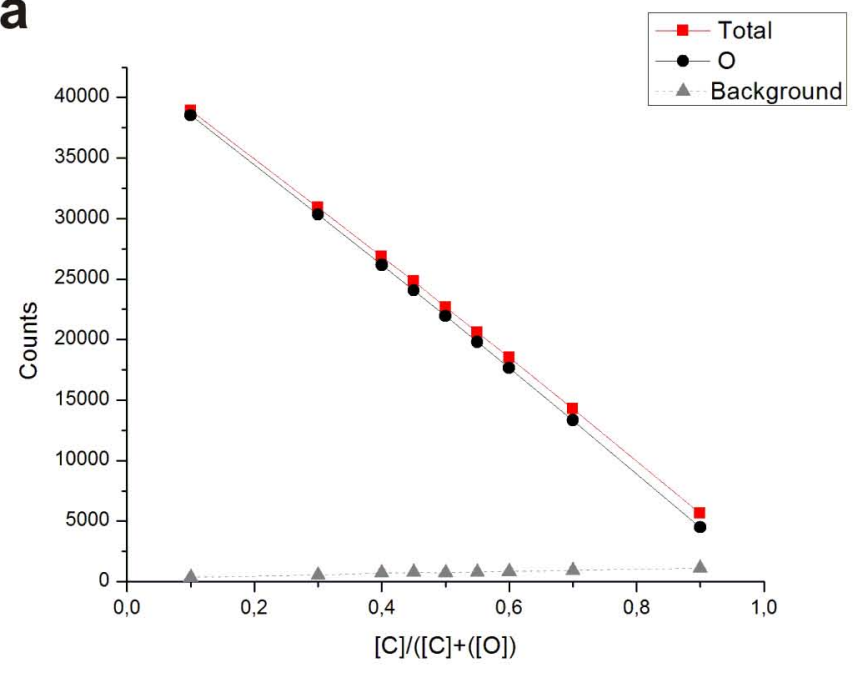

b

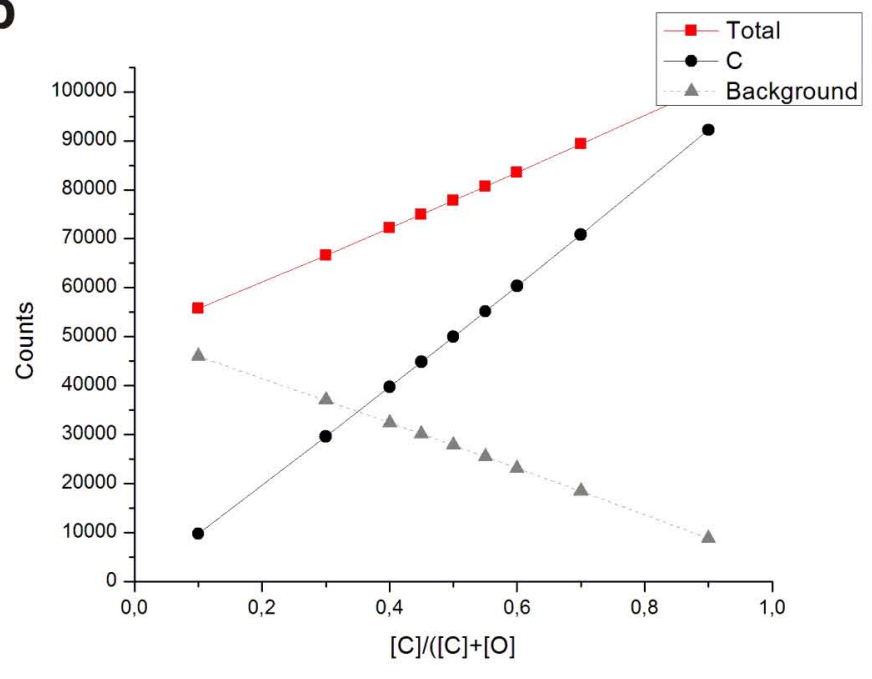




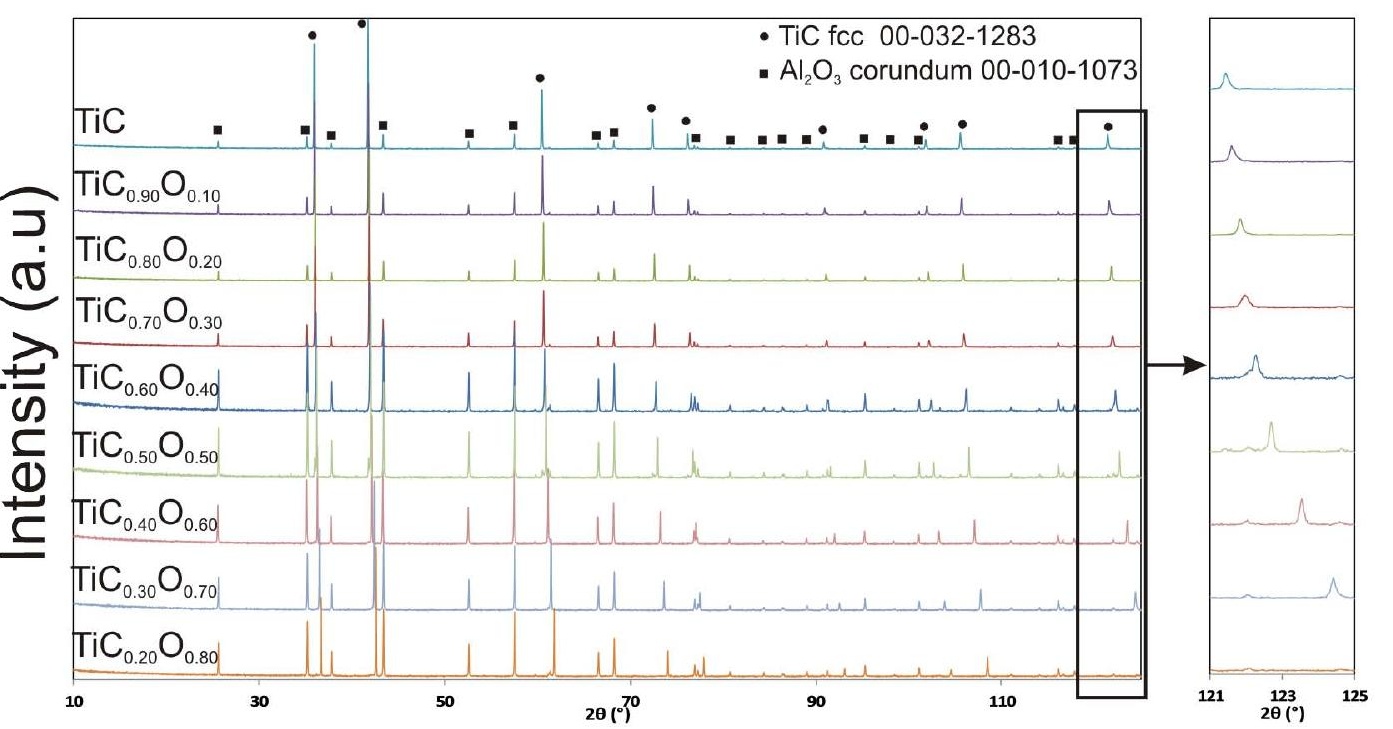




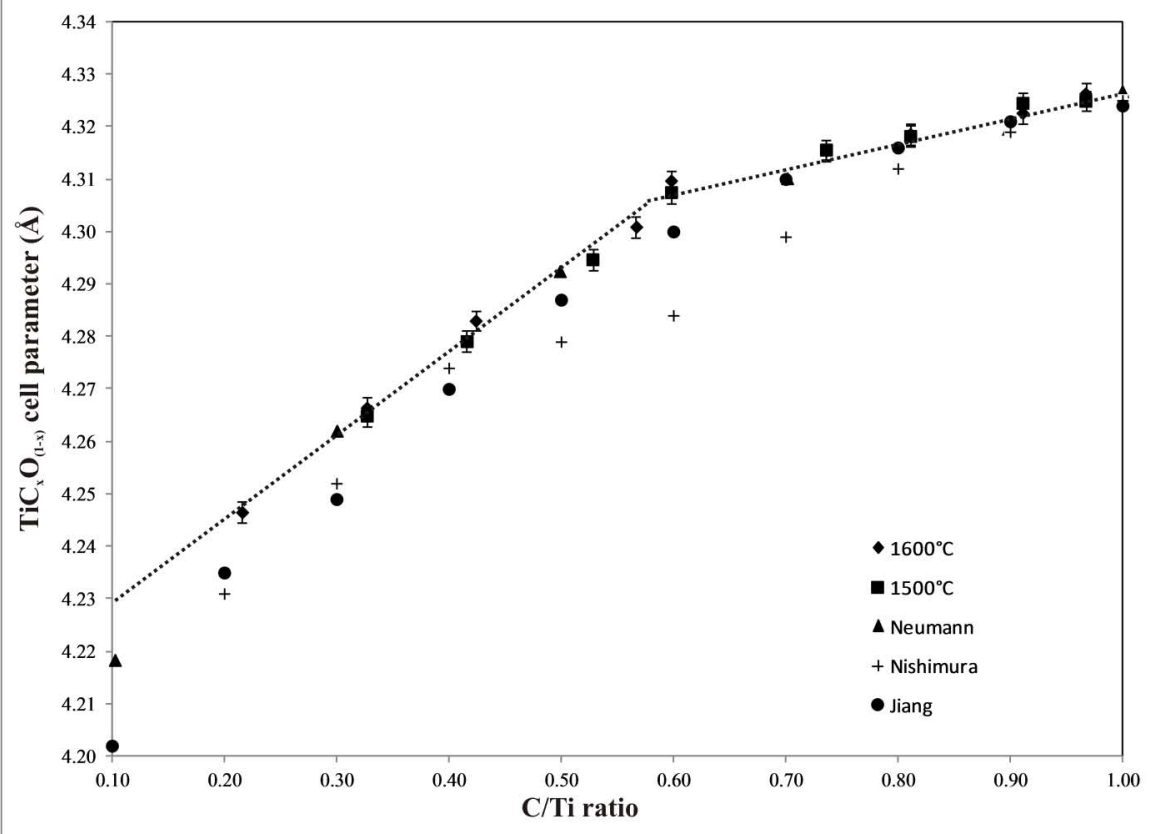

